\title{
Simultaneous localization of multiple unknown \\ CSMA-based wireless sensor network nodes using a mobile robot with a directional antenna
}

\author{
Dezhen Song • Chang-Young Kim • Jingang Yi
}

Published online: 18 September 2009

(C) Springer-Verlag 2009

Erratum to: Intel Serv Robotics

DOI 10.1007/s11370-009-0046-7

The original version of this article unfortunately contained a mistake. The sequence of the author names was incorrect.

The online version of the original article can be found under doi:10.1007/s11370-009-0046-7.

D. Song · C.-Y. Kim

Computer Science and Engineering Department,

Texas A\&M University, College Station,

TX 77843, USA

e-mail: dzsong@cse.tamu.edu

C.-Y. Kim

e-mail: kcyoung@neo.tamu.edu

J. Yi (凶)

Mechanical and Aerospace Engineering Department,

Rutgers University, Piscataway, NJ 08854, USA

e-mail: jgyi@ rutgers.edu 